\title{
Fernando el Católico y la reforma de los benedictinos y benedictinas españoles (1474-1516)
}

\author{
Ferdinand II and the reform of the Spanish \\ Benedictines (1474-1516)
}

Ernesto ZARAGOZA PASCUAL

Correspondiente de las RR. AA. de la Historia

y de Bones Lletres y de S. Rosendo

ernestzar@terra.com

\begin{abstract}
In this paper, the author provides a chronological analysis of the vicissitudes in the reform of monastic, economic and organizational life of the monasteries of Benedictine monks and nuns, covering the three existing congregations in Spain during the time of the Catholic Monarchs (1474-1516): the Benedictine Claustral Congregation of Compostela, the Benedictine Claustral Congregation of Toledo and the Benedictine Claustral Congregation of Tarragona and Zaragoza. All monasteries of the first two were slowly integrated into the Observant Congregation of San Benito of Valladolid. Only three of the monasteries of the Congregation of Tarragona and Zaragoza were assimilated, despite the great interest of the Catholic Monarchs.
\end{abstract}

Keywords: Benedictine order, Ferdinand II the Catholic, religious congregations, reform.
Resumen: En este trabajo el autor sigue cronológicamente las vicisitudes de los reforma de la vida monástica, económica y organizativa de los monasterios de monjes y monjas benedictinos de las tres Congregaciones existentes en España en tiempo del Rey Católico (1474-1516), a saber: Congregación Benedictina Claustral Compostelana, Congregación Benedictina Claustral Toledana, y Congregación Benedictina Claustral Tarraconense y Cesaraugustana, de las cuales todos los monasterios de las dos primeras fueron integrándose poco a poco en la Congregación Observante de San Benito de Valladolid, pero de los de la Congregación Tarraconense y Cesaraugustana, sólo tres llegaron a integrarse en ella, a pesar del gran interés de los Reyes Católicos.

Palabras clave: Orden benedictina, Fernando el Católico, congregaciones religiosas, reforma

Comenzamos nuestro trabajo diciendo que la necesidad de reforma en los monasterios benedictinos era patente, sobre todo después del Cisma de Occidente (1378-1416), que tuvo repercusiones muy negativas en la vida de los monasterios, en primer lugar, porque las comunidades se dividieron en bandos, unos partidarios del papa de Roma y otros del de Aviñón. Además, el papa Benedicto XIII, en 1397 se había reservado el nombramiento de abades y demás cargos princi- 
pales de las abadías, la administración de muchas de los cuales encomendó -de aquí viene el nombre de abades comendatarios- a personas eclesiásticas ajenas a la orden o civiles, oficialmente lo hizo para que defendiesen los monasterios de los que querían usurpar sus bienes, pero de hecho era para pagar servicios prestados. Esto hizo que, los monasterios que daban su obediencia al papa de Roma, sus comunidades podían elegir libremente a sus abades, que luego eran confirmados por aquel papa, pero los que obedecían al papa de Aviñón no podían elegir a sus prelados y si una parte de la comunidad partidaria del papa de Roma los elegía, se producían luchas intestinas por causa de la duplicidad de abades en el monasterio. Los abades comendatarios, dejaban en los monasterios un prior claustral, que gobernara la comunidad en su nombre, pues ellos sólo cuidaban de cobrar las rentas de la mensa abacial y frecuentemente no cumplían con las obligaciones de mantener los edificios y ayudar al sostenimiento de sus monjes. Así vemos cómo decae la disciplina, se diluye el patrimonio y los monasterios tienen muy pocos monjes profesos, a menudo sólo los precisos para servir los distintos oficios claustrales, sirviéndose de clérigos beneficiados para la cura de almas fuera del monasterio. Algunos de los monjes vivían amancebados y con hijos, otros salían del monasterio para pescar y cazar, muchos juegan a dados o naipes, visitan tabernas, etc ${ }^{1}$.

La reforma comenzó a dar sus pasos en Castilla, gracias al rey Juan I, que en 1390 fundó el monasterio de San Benito en su real alcázar de Valladolid para benedictinos con voto de clausura al estilo de las monjas de Santa Clara, que daría lugar a la reforma observante de los monasterios de benedictinos y benedictinas sobre todo en tiempo de los Reyes Católicos, que con la ayuda de Roma y del brazo secular - puesto que a menudo los reformadores hallaron una resistencia violenta- para implantar la reforma observante, tan distinta en su organización de la de los monasterios claustrales, heredada de Cluny. Así, en Galicia, la reforma observante se comenzó en los primeros años del reinado de Fernando el Católico, pero sólo avanzó decididamente después de la bula Quanta in Dei Ecclesia (27-VII1493), con la intervención los priores vallisoletanos, singularmente fray Juan de San Juan de Luz (1488-97), fray Rodrigo de Valencia (1498-99) -que perdió su

1 Ernesto Zaragoza Pascual, Documentos inéditos sobre la reforma de los monasterios benedictinos gallegos (1496-1499), en Compostellanum, 14 (1998), p. 844; ID., Proceso de reforma contra el abad de Samos y Monforte (1498-99), en Estudios Mindonienses, 16 (2000), pp. 421-465; ID., La reforma monástica del monasterio de Santa María de Mezonzo (1498-99), en Compostellanum, XXXVIII (1993), pp. 395-433; ID., Proceso de Reforma contra el abad de San Mamed de Seavia (1498-99), ibid., vol. XLII (1997), pp. 185-209. 
vida envenenado-, fray Pedro de Nájera (1499-1518), y fray García de Cisneros para Cataluña $(\dagger 1610)$.

Como en Galicia los monasterios de benedictinas sólo tenían una, dos o tres monjas y éstas llevaban casi todas una vida personal o monástica nada edificante, el reformador fray Rodrigo de Valencia suprimió todos los monasterios existentes y recogió a sus abadesas y monjas en el nuevo monasterio de San Paio de Antealtares, de Santiago de Compostela, único monasterio de benedictinas que había de quedar para toda Galicia. En efecto, fundó este monasterio en enero de 1499 con monjas observantes de los monasterios burgaleses de San Salvador del Moral y la abadesa Beatriz de Acuña del de Santa María de los Ausines. Y a este monasterio fueron unidos los de San Salvador de Albeos, San Pedro de Ramirás, San Juan de A Cova, San Esteban de Chouzán, San Miguel de Eiré, Santa María de Pesqueiras, San Fiz de Cangas, San Xillao de Lobios, San Salvador de Trives, San Pedro de Lobás, San Pedro de Dozón, San Pedro de Ansemil, San Andrés de Órrea y San Miguel das Negradas. Y tras ser procesadas varias de sus abadesas, éstas fueron recluidas en San Payo, aunque algunas intentaron regresar a sus respectivos monasterios ${ }^{2}$. Esta fundación de San Payo y la unión a él de estos monasterios fue confirmada por el papa Julio II el 1 de octubre de 1504 y de nuevo el 1 de abril de $1514^{3}$.

Siguiendo la tradición cluniacense, en los monasterios de benedictinos claustrales había dos clases de monjes y monjas, los oficiales: prior, camerario -mayordomo-, sacristán, enfermero, limosnero, obrero, hospedero, refitolero, pabordes y priores de prioratos dependientes a menudo con residencia en la abadía de la que

2 Ernesto Zaragoza Pascual, Reforma de los monasterios de Lobaes, Dozón y Ansemil (1498-99), en Miscelánea Samonense. Homenaje al P. M. Arias, Lugo, 2001, pp. 301-331; ID., Procesos de reforma contra la abadesa de Lobios y la priora de Pesqueiras, en Compostellanum, XLI (1996), pp. 357-386; ID., Proceso de reforma contra la abadesa de San Salvador de Albeos (1499), en Museo de Pontevedra, 51 (1997), pp. 563-590; ID., Proceso de reforma contra el abad de Lérez (1499), en Museo de Pontevedra (en prensa); ID., Documentos inéditos sobre la reforma de los monasterios benedictinos gallegos (14961499), en Estudios Mindonienses, 24 (1998), pp. 807-844; ID., Documentos inéditos sobre la reforma de los monasterios benedictinos gallegos (1493-1513), en Compostellanum, XLIV (1999), pp. 77-103; ID., Documentos inéditos sobre la reforma de algunos monasterios benedictinos gallegos (1496-1530), en Diversarum rerum, 7 (2012), pp. 171-191; ID., Catálogo de documentos sobre la reforma de los monasterios benedictinos de Galicia y otros (1487-1534), en ibid., 3 (2008), pp. 63-85; ID., Documentos inéditos sobre algunos monasterios gallegos (1491-1598), en ibid., 5 (2010), pp. 63-88; ID., Índice documental de los monasterios benedictinos de Monforte, Chantada, Cebrero y Moraime (ss. IX-XVIII), en ibid., 8 (2013) pp. 231-248.

3 García M. Colombàs, Las señoras de San Payo. Historia de las monjas benedictinas de San Pelayo de Antealtares, Santiago de Compostela, 1980; Ernesto ZARAgOZA PASCUAL, Abadologios de algunos monasterios de benedictinas de España, en Compostellanum, L (2005), p. 452. 
dependían, y los monjes claustrales, que eran pocos y no tenía oficio alguno, en espera de que se produjera alguna vacante. Los primeros vivían de las rentas de sus respectivos oficios, que administraban, y los segundos recibían una porción diaria, el vestuario, algunos dineros por la asistencia al coro y los estipendios de misas y aniversarios. Cada monasterio tenía también algunos criados para el servicio común y particular de cada oficio, pues los oficiales vivían en casas o aposentos particulares, aunque situados todos dentro de la cerca del monasterio, y el abad en su «palacio».

Era costumbre que el lunes de Pentecostés los monjes realizaran la ceremonia llamada de la «desapropiación», consistente en presentar al abad un memorial con la relación de todo lo que cada uno tenía en su casa o celda, y las cuentas de la administración de su oficio. También el abad presentaba los suyos a la comunidad. Luego el abad aprobaba los memoriales y dejaba en uso un año más a los monjes todo lo contendo en ellos. Además el jueves santo -y lo mismo antes de morir-, los oficiales ponían las llaves de sus oficios en manos del abad y éste se las devolvía para que siguieran sirviéndolos. Así salvaban el voto de pobreza, pues todo cuanto tenían en uso era con permiso del abad. El abad recibía las rentas de la mensa abacial y los diezmos de las parroquias y las primicias del cura que las servía, a quien tenía que sustentar. Las tierras eran arrendadas al seglar que más pagaba por ellas.

Hay que hacer notar, que el hecho de que las rentas estuviesen repartidas entre los diversos oficios claustrales, suponía una grave dificultad para emprender obras de gran envergadura en los monasterios, ya que suponían grandes dispendios, no así en los observantes cuya economía era única y administrada por el monje mayodomo. En general las comunidades -que estaban mayoritariamente formadas por hijos e hijas de gente noble y adinerada-, no podían admitir más monjes que los precisos para ocupar los oficios claustrales, lo cual repercutía negativamente en el esplendor del culto por falta de personal, cuya escasez era suplida con clérigos beneficiados externos, que se unían a los monjes en el coro, algunos de los cuales tenían también la cura de almas de las parroquias dependientes de los monasterios ${ }^{4}$.

Los defectos más comunes que había en los monasterios de monjas gallegos y asturianos al llegar los reformadores vallisoletanos eran que los clérigos y seglares familiares entraban en los aposentos de la clausura y las monjas salían

4 Ernesto Zaragoza Pascual, Història de la Congregació Benedictina Claustral Tarraconense y Cesaraugustana, op. cit., pp. 10-11. 
de ella para asistir a bautizos y entierros y la vida moral de unos y otras a menudo era desastrosa, perdurando esta situación en los monasterios del norte de Portugal hasta bien entrado el siglo XVI ${ }^{5}$. De hecho la vida comunitaria en el refectorio y dormitorio apenas existía, el culto divino era descuidado y a menudo negativa la administración del patrimonio y de las rentas, pues cada monje y monja oficial disponía a su arbitrio de las rentas y bienes asignados a su oficio claustral.

En 1493 D. Alonso Carrillo de Albornoz, obispo de Catania, que a petición de los Reyes Católicos fue nombrado por el papa visitador y reformador de la orden de San Benito en España, delegó la reforma de los benedictinos de Galicia y del Bierzo en el prior de San Benito de Valladolid fray Juan de San Juan de Luz, que entre octubre de 1494 y el 26 de marzo de 1495 tomó posesión de todos y cada uno de los monasterio gallegos y el 1 de diciembre de 1495 subdelegó su oficio de visitador y reformador en fray Juan de Melgar, abad de San Martín Pinario de Santiago de Compostela y en fray Diego de la Plaza, prior del monasterio del Cebrero. Los monjes y monjas de la Congregación Benedictina Claustral Compostelana -de la que no ha quedado ningún documento oficial, como constituciones, actas de capítulos generales o de visitas, nombres de los presidentes y visitadores, etc., porque los observantes los hicieron desaparecer- ${ }^{6}$, en principio no quisieron aceptar la nueva observancia y defendieron aquí y en Roma su forma de vida y gobierno, aprobados en sus capítulos generales y confirmados por los papas. Pero no pudieron sobrevivir a la embestida de la Observancia, lo mismo que la Congregación Benedictina Claustral Toledana, que agrupaba todos los monasterios benedictinos de Burgos, Palencia y León. Únicamente sobrevivió la Congregación Benedictina Claustral Tarraconense y Cesaraugustana -de la que trataremos más abajo-, que con la ayuda de Roma pudo continuar con su forma de vida y de gobierno hasta 1835 , aunque progresivamente reformados en muchos puntos, merced a las disposiciones de sus capítulos provinciales y a finales del siglo XVI, a tenor de la bula de Clemente VIII, Sacer et religiosus monachorum

5 Ernesto Zaragoza Pascual, La Congregación benedictina observante de Valladolid y la reforma de los monasterios benedictinos portugueses (1390-1598), en Os beneditinos na Europa, Sto. Tirso, Portugal, 1998, pp. 237-246; ID., Fray Pedro de Chaves, reformador de los monasterios benedictinos portugueses, conferencia a VII Coloquios Histórico de Extremadura, Trujillo (23-IX-77), Ms. Archivo Parroquial de Trujillo. Resum en el folleto del mismo coloquio; ID., Reforma de los benedictinos portugueses (1564-65), en Bracara Augusta, XXXV/79-80 (1981), pp. 275-290; ID., Reforma de los benedictinos portugueses (1588-1589), en Theologica, XVII (1983), 78 pp.

6 Según testimonio del célebre benedictino fray Martín Sarmiento, Archivo de la Universidad de Santiago de Compostela, Ms. 585, fol. 147s. 
status (13-VIII-1592), de cuyos monasterios sólo los de Montserrat y Sant Feliu de Guíxols aceptaron la observancia vallisoletana ${ }^{7}$.

De hecho, la Congregación Benedictina Claustral Compostelana celebró su último capítulo en San Martín de Santiago el 12 de diciembre de 1498 convocado por fray Rodrigo de Valencia, en el cual «fueron notificadas a todos los abbades y priores de la Orden de Sant Benito» las bulas de reforma, que le acreditaban como reformador apostólico de todos los monasterios de monjes y monjas benedictinos de Galicia. Y así desapareció, igualmente que la Congregación Benedictina Claustral Toledana ${ }^{8}$ ante el avance arrollador de los observantes -respaldados por la Santa Sede y por los monarcas y nobles españoles-, que aportaban solidez, mejor organización y administración, más pobreza personal, más espiritualidad litúrgica y monástica, intensa vida común y formación. La Observancia vallisoletana se implantó, no sin diversas resistencias, en todos los monasterios del Norte de España (Galicia, Asturias, León, Castilla y la Rioja) a caballo de los siglos XV-XVI, se consolidó en tiempos de Carlos V y culminó en tiempos de Felipe II en $1563^{9}$.

Antes de 1494 los monasterios se reformaban con sus propios monjes, ajustando la vida de comunidad a las disposiciones de la regla benedictina según los usos de la observancia vallisoletana. Después de la mencionada fecha, la observancia vallisoletana se implantaba con monjes observantes, después de hacer una concordia con el abad claustral o comendatario por la que éste, al tiempo que permitía la introducción de la observancia en su monasterio, renunciaba al gobierno y administración del mismo, a cambio de una pensión anual vitalicia, con la condición de que a su muerte el monasterio fuera regido por abades trienales elegidos por la comunidad. Y el papa aprobaba la concordia, aunque mientras vivía el abad titular el monasterio era regido por un prior observante llamado presidente, y a su muerte el abad general de Valladolid elegía al primer abad trienal y pedía al papa una bula de confirmación de la elección abacial y de la unión del monasterio a la Congregación de Valladolid. De manera que hay que distinguir entre la primera bula, por la cual se introducía en el monasterio la observancia vallisoletana y la segunda, que le unía definitivamente a la Congregación de Valladolid.

7 Ernesto Zaragoza Pascual, Los Generales de la Congregación de Valladolid, II, Silos, 1976, pp. 352-355; ID., Documentación inédita sobre la reforma de la Congregación de Valladolid (15601567), en Studia Monastica, 43 (2001), pp. 83-178.

8 Ernesto Zaragoza Pascual, La Congregación Benedictina Claustral Toledana, en Bol. Institución Fernán González, de Burgos, 214 (1997), pp. 47-60.

9 Ernesto Zaragoza PaSCUAL, Los generales, op. cit., pp. 352-355. 
Desde el siglo XIV, la Congregación Benedictina Claustral Tarraconense y Cesaraugustana estaba divida en dos provincias, a saber: Tarraconense, que agrupaba en el Rosellón las abadías de Sant Miquel de Cuixà ${ }^{10}$, Sant Martí del Canigó ${ }^{11}$ y Santa Maria de Arles ${ }^{12}$, en Cataluña las de: Sant Lloreç de Bagá ${ }^{13}$, Sant Pau del Camp de Barcelona ${ }^{14}$, Sant Pere de Besalú ${ }^{15}$, San Salvador de Breda ${ }^{16}$, Sant Pere de Camprodón ${ }^{17}$, Sant Andreu de Sureda y Sant Quirze de Colera ${ }^{18}$, Sant Miquel de Cuixà, Sant Pere de Galligants ${ }^{19}$, Santa Maria de Gerri ${ }^{20}$, Sant Llorenç de Sous ${ }^{21}$, Santa Cecilia de Montserrat ${ }^{22}$, Sant Llorenç del Munt ${ }^{23}$, Sant Pere de la Portella ${ }^{24}$,

10 François FonT, Histoire de l'abbaye royal de Saint-Michel de Cuxà, Perpinyà, 1882; J. VAILLET, Le monastère de Saint-Michel-de-Cuxà, Prades, 1957; Alexandre MASOlIVER, La comunitat de Fontfreda a Cuixà i la restauració monàstica de Poblet, en Studia Monastica, 39 (1977), pp. 195-218.

11 Francisco Monsalvatje y Fossas, Monasterio de San Martín de Canigó, Olot, 1899; Françóis FONT, Histoire de l'Abbaye de Saint Martin de Canigou, Perpinyà, 1903.

12 Francisco MOnSalvatje y Fossas, Santa María de Arlés: Noticias históricas, VII, Olot, 1896; XXIV, 103-09; Joseph GIBERT, Aperçu bistorique sur l'abbaye de Arles sur Tech, Céret, 1922.

13 Jordi BolÒS-Montserrat PAGÈs PARETAS, El monestir de San Llorenç prop Bagà, Barcelona, 1986.

14 Jacques ViguÉ, El monestir romànic de Sant Pau del Camp, Barcelona, 1974; Josefa MuTGÉ ViveS, El monestir de Sant Pau del Camp de Barcelona en la segona meitat del segle XV: Miscel.lània de Textos Medievals, 8 (1996), pp. 393-461.

15 Amand SÉquestra, Sant Pere de Besalú, Abadia Reial de la Congregación Claustral Tarraconense (977-1835), Santa María del Mont, 1934, Francisco Monsalvatje y FosSAS, El Condado de Besalú, en Noticias históricas, vols. I, II, X, XI, XII, XII, Olot, 1889-1906.

16 Jaume COLl CASTANYER, Breda històrica i actual, Granollers, 1971.

17 Francisco Monsalvatje y Fossas, Monasterio de San Pedro de Camprodón, Olot, 1895; Antonio Serrallach, San Pedro de Camprodón, Barcelona, 1896; Miquel dels Sants Gros Y Pujol, Sant Pere de Camprodon, un monestir del comtat de Besalú: Art i cultura als monestirs del Ripollès, Montserrat, 1995, 69-87.

18 Francisco Monsalvatje y Fossas, Monasterio de San Andrés de Sureda y San Quirico de Colera, Olot, 1896; Juan Subias GaLTER, El monestir de Sant Quirze de Colera, en Anales del Instituto de Estudios Ampurdaneses, I (1959), p. 77ss.

19 Josep Calzada, Sant Pere de Galligans, Girona, 1983.

20 Jaume PASQUAL, Principios, progresos y decadencia del Real Monasterio de San Vicente (boy Ntra. Sra.) de Gerri: prerrogativas y excelencias de sus abades y cabildo y catálogo de todos sus prelados: en Revista de Ciencias Históricas, 1 (1880), pp. 54-61; Llorenç SÁNCHEZ, El monasterio de Santa Maria de Gerri. Passat i present de la gran abadia benedictina de Pallars (1937); Enric MoLINÉ, Els abats de Gerri des de 1454 fins el 1835, en Collegats, 9 (1996), pp. 145-161.

21 L. M. CALLÍS-J. PUIGFERRAT, Monografia per recordar un monestir oblidat: elmonestir de Sant Llorenç de Sous, Girona, 1985; Joan CARRERAS I PÉRA, El Mont. Abir un monestir, avui un santuari, Col. Sant Feliu, núm. 4, Olot, 1988.

22 Josep Puig i Cadafalch, Santa Cecília de Montserrat, en Studia Monastica, 19 (1977), pp. 19-25.

23 Antoni VERGÉs MARISSÓ, Sant Llorenç del Munt: Son passat, son present i porvenir, Barcelona, 1871; Francesc SolÀ, Història de Sant Llorenç del Munt, Barcelona, 1980; Antoni FERRANDO, El monestir de Sant Llorenç del Munt i les seves possessions, Montserrat, 1987.

24 Ramón ANGLERILl, Història de Santa Maria de la Quar, Barcelona, 1887; Joan SANTAMARÍa RoVIRA, Memòries del monestir de Sant Pere de la Portella, de tot el seu abadiat i banonia, Solsona, 1936. 
Santa Maria de Ripoll ${ }^{25}$, Sant Pere de Roda ${ }^{26}$, Sant Cugat del Vallés ${ }^{27}$, Santa Maria de Serrateix ${ }^{28}$, Sant Sadurní de Tavèrnoles ${ }^{29}$, Santa Maria de Roses ${ }^{30}$, Santa Maria de Amer $^{31}$, Sant Esteve de Banyoles ${ }^{32}$ y el priorato de Santa Maria de Meià ${ }^{33}$, además de los tres de monjas de Sant Daniel de Gerona ${ }^{34}$, Sant Pere de les Puel.les ${ }^{35}$ y Sant Antón y Santa Clara de Barcelona ${ }^{36}$. Y la provincia Cesaraugustana contaba con las abadías en Aragón, a saber: San Juan de la Peña ${ }^{37}$, Ntra. Sra. de Alaón ${ }^{38}$, San Victorián de Asán ${ }^{39}$ y la de monjas de Jaca, y en Navarra las abadías de monjas de Santa María Magdalena de Lumbier o Lisabe y de San Benito de Estella ${ }^{40}$.

La Congregación Observante de Valladolid, poco a poco llegó a reunir el resto de las abadías de España, aunque casi todas estaban situades en su mitad

25 Josep María Pellicer, Santa María del monasterio de Ripoll, Mataró, 1888; Josep RIUS SERRA, Correspondencia epistolar entre Don Roque Olzinellas y el P. Fosé de La Canal, en Analecta Sacra Taraconensia, XVIII (1945), pp. 189-217; Ferran MARTÍ CAMPS, Epistolario familiar de Don Pedro Sancho y Olives, abad de Santa María de Ripoll, en Revista de Menorca, 35 (1948), pp. 79-81.

26 Andrés Simón Portero, Descripción del Real Monasterio de San Pedro de Roda, Barcelona, 1752; Joaquim Guitert Fontseré, Monestir de Sant Pere de Roda, Barcelona, 1927; Antoni Papell, San Pedro de Roda, Figueres, 1930; Joan Subias Galter, El monestir de Sant Pere de Roda, Barcelona, 1948, pp. 176-182; Joan Pujol, Sant Pere de Rodes, Figueres, 1999; Raúl PÉREZ POZA, Sant Pere de Rodes: un capbreu de 1419, en Annals de l'Institut d'Estudis Empordanesos, 29 (1996), pp. 99-157.

27 Benet Moxó, Memorias históricas del Real Monasterio de San Cugat del Vallés, Barcelona, 1790; Elías Rogent Callejero, Sant Cugat del Vallès, Barcelona, 1881; Josep de PeraY, Sant Cugat del Vallès, Barcelona, 1932.

28 Ignasi Feliu DE TRAVY, El monestir de Santa Maria de Serrateix, Granollers, 1977; Jordi BolósMontserrat PAGÈs PARETAS, El monestir de Santa Maria de Serrateix i la parròquia de Sant Pere, en Quaderns d'Estudis Medievals, vol. II (1980).

29 J. Nogués, Història del monestir de Sant Sadurní de Tavèrnoles, Barcelona, 1973.

30 Cfr. Ernesto Zaragoza Pascual, Catàleg dels monestirs catalans, col. Scripta et Documenta, vol. 55, Montserrat, 1997 , p. 61.

31 Esteve Pruenca I Bayona, Diplomatari de Santa Maria d'Amer, Barcelona, 1995; Ernesto ZARAGOZA PASCUAL, Catàleg dels monestirs catalans, op. cit., pp. 19-21; ID., Abaciologi Benedictí de la Tarraconense, op. cit., pp. 35-41.

32 Ernesto Zaragoza Pascual, Història de la Congregació Benedictina Claustral Tarraconense y Cesaraugustana, op. cit., p. 319 (con abundante bibliografía).

33 Gaspar Roig Jalpí, Tratado de las excelencias de Santa María de Meyán, Barcelona, 1664. Josep Nogués Estany, Història del monestir de Sant Sadurní de Tavèrnoles, Barcelona, 1973.

34 Ernesto Zaragoza Pascual, Història de la Congregació Benedictina Claustral Tarraconense y Cesaraugustana, op. cit., pp. 328-329.

35 ID., ibid., p. 321 (con bibliografía)

36 ID., ibid., p. 320 (con bibliografía).

37 ID., ibid., pp. 334-335 (con bibliografía).

38 ID., ibid., p. 315 (con bibliografía).

39 ID., ibid., pp. 341-342 (con bibliografía).

40 Julio Campos, Fray Prudencio de Sandoval y San Benito el Real de Estella, en Príncipe de Viana, 33 (1948), pp. 516-517. 
norte, a saber en Galicia: San Martín Pinario y San Payo de Antealtares de Santiago de Compostela, San Juan de $\mathrm{Poyo}^{41}$, San Salvador de Lérez, San Pedro de Tenorio, San Salvador de Celanova ${ }^{42}$, San Esteban de Ribas de Sil ${ }^{43}$, San Vicente del Pino de Monforte de Lemos, San Julián de Samos ${ }^{44}$ y San Salvador de Lorenzana ${ }^{45}$; en Asturias: San Vicente ${ }^{46}$, Santa María de la Vega y San Pelayo de Oviedo, éstos dos últimos de monjas, San Juan Bta. de Coriass ${ }^{47}$, San Salvador de Celorio ${ }^{48}$, San Salvador de Cornellana, San Pedro de Villanueva ${ }^{49}$ y Santa María de Obona ${ }^{50}$; en León tenía las abadías de San Claudio de León ${ }^{51}$, San Benito de Sahagún ${ }^{52}$, San Pedro de Montes ${ }^{53}$, San Andrés de Espinareda, San Pedro de Eslonza, San Vicente de Salamanca, San Benito de Zamora y el de monjas de Santa Maria de Vega de la Serrana; en Castilla la Vieja tenia las abadías burgalesas de Oña ${ }^{54}$, San Juan de Burgos ${ }^{55}$, San Pedro de Cardeña ${ }^{56}$, San Pedro de Arlanza,

41 José Santiago Crespo del Pozo, El monasterio de Poyo, Pontevedra, 1968; Sergio VázQueZ Rouco, San Xoan de Poio. Monasterio, coto, parroquia, Pontevedra 1998, con muchos errores en nombres y fechas de abades.

42 Benito de OYA, Epitome de los augmentos y sucesos del insigne monasterio de Celanova, AHN, Cód. 1429 (1620); Benito de la CUEva, Historia de los monasterios y prioratos anejos a Celanova, ibid., Clero, Lib. 19774, publicado por María Teresa GonZÁlez BALASCH, Granada, 1991; VV. AA. San Salvador de Celanova, Edilesa, León, 2001; Hipólito de SA BRAVO, El monacato en Galicia, 2 vols., La Coruña, 1972.

43 Pedro Duro PeÑa, El monasterio de San Esteban de Ribas de Sil, Ourense, 1977.

44 Maximino ARIAS CUENLlas, Historia del monasterio de San fulián de Samos, Samos 1992.

45 Eduardo LENCE SANTAR, Real monasterio de San Salvador de Lorenzana, Mondoñedo, 1943.

46 Ma. Josefa SANZ FUENTES-Juan Ignacio RUIZ DE LA PEÑA, Colección diplomática del monasterio de S. Vicente de Oviedo (ss. XIII-XV), I, Oviedo, 1991.

47 José Cuervo, El monasterio de Real monasterio de San fuan Bta. de Corias, Salamanca, 1915.

48 Elviro Martínez FernándeZ, El monasterio de Celorio, Oviedo, 1981.

49 Juan del SaZ, Manuscrito de San Pedro de Villanueva, J. M. GonZÁleZ, J. ManZanares y M. G. MARTínEZ (eds.), Oviedo, 1955; Ceferino ALONSO FERNÁNDEZ, Reseña bistórico-descriptiva del monasterio y parroquia de San Pedro de Villanueva, Gijón, 1915.

50 Constantino CABAL RUBIERA, El monasterio de Obona, en Boletín del Instituto de Estudios Asturianos, vol. XI, 1-9; XII, 3-41; XIII, 215-235; XVI, 299-301.

51 Eloy DíAZ-JiMÉNEZ, Historia del Real monasterio de San Claudio de León, Madrid, 1930.

52 Romualdo de Escalona, Historia del Real Monasterio de Sahagún, Madrid, 1782; Juan Manuel Cuenca Coloma, Sahagún. Monasterio y Villa, Valladolid, 1985.

53 Joaquín Herrezuelo, Historia del monasterio de San Pedro de Montes (s. XIX), en Archivo de Silos, s. n.

54 Enrique Herrera OrIa, Oña y su Real Monasterio, Madrid, 1917.

55 El «Libro Becerro» del monasterio de San Fuan de Burgos, publicado por M. Muñoz en el Boletín de Estadística del Ayuntamiento de Burgos, Burgos, 1950.

56 Francisco de Berganza, Antigüiedades de España, 2 vols., Madrid, 1719-21; Jesús ÁLvarez ÁLVAREZ, Cardeña y sus hijos, Burgos, 1951; Jesús MARRODÁn, San Pedro de Cardeña. Historia y arte, Burgos, 1993. 
Santo Domingo de Silos ${ }^{57}$, Santa María de Obarenes $^{58}$ y Nuestra Señora del Espino ${ }^{59}$, además de las palentinas de San Zoilo de Carrión de los Condes, San Isidro de Dueñas $^{60}$, Ntra. Sra. de la Misericordia de Frómista y las vallisoletanas de San Benito el Real de Valladolid, cuna y cabeza de la Congregación de su nombre ${ }^{61}$ y Ntra. Sra. del Bueso; en la Rioja tenía las tres grandes abadías de Santa María la Real de Nájera $^{62}$, San Millán de la Cogolla ${ }^{63}$, y Santa María de Valvanera ${ }^{64}$, en Navarra la de Irache ${ }^{65}$; y en Cataluña las de Montserrat ${ }^{66}$, Sant Benet de Bages ${ }^{67}$, Sant Genís

57 Gaspar Ruiz de Montiano, Historia de Sto. Domingo de Silos, en el Archivo de Silos, Ms. 21 (1615); Mario FÉrotin, Histoire de l'Abbaye de Silos, París, 1897; Ernesto ZaragOZa Pascual, Abadologio de Santo Domingo de Silos, Burgos, 1998.

58 Juan DE SAlaZAR, Historia del monasterio de Obarenes, Ms. en el archivo de Silos, Documentos varios, I, ff. 154r-163v; Alfonso ANDRÉS, El monasterio de Santa María de Obarenes, en Boletín de la Institución Fernán González, de Burgos, núm. 160ss (1963-64).

59 Luciano Huidobro, Nuestra Señora del Espino, Lérida, 1922; Andrés GoY, El Espino y su comarca, Madrid, 1940.

60 Damián M. ${ }^{a}$ YáÑEZ, Historia del Real Monasterio de San Isidro de Dueñas, Palencia, 1969; Luis TARRACO, Notas para la historia del Monasterio de San Isidro de Dueñas, en Cistercium, XXIV (1988), pp. 365-381.

61 José Luis RodrígueZ, Historia del monasterio de San Benito el Real de Valladolid, Valladolid, 1981, que hasta 1610 sigue los tres primeros volúmenes de nuestra citada obra: Los Generales de la Congregación de San Benito de Valladolid, 6 vols., Silos, 1973-80. Añádase nuestro Abadologio del monasterio de San Benito el Real de Valladolid, en Investigaciones históricas, 23 (2003), pp. 203-260.

62 Juan DE SALAZAR, Náxara ilustrada (s. XVII), Logroño, 1987.

63 Miguel Cárcamo, Historia de San Millán de la Cogolla, Ms. de 1779, en el mismo monasterio; Joaquín PEÑa, Páginas emilianenses, 2. ${ }^{a}$ ed., San Millán de la Cogolla, 1980.

64 Francisco Javier GARCía TuRZA, El monasterio de Valvanera en la Edad Media. Siglos XIV-XV, Madrid, 1990; Benito Rubio, Historia del Venerable y Antiquísimo Santuario de Ntra. Sra. de Valvanera, Logroño, 1761 y 1798; Agustín URCEY PRADO, Historia de Valvanera, Logroño, 1932; Alejandro PÉrez Alonso, Historia de la Real Abadía de Ntra. Sra. de Valvanera, en la Rioja, s. 1., s. a. [1971]; Ernesto ZARAgOZa PASCUAL, Abadologio del Monasterio de Nuestra Señora de Valvanera (ss. X-XX), en Studia monastica, 43 (2001), pp. 333-372, con las rectificaciones de nuestro Abaciologi Benedictí de la Tarraconense, Barcelona, Balmesiana, 2002.

65 Javier IBARRA, Historia del monasterio y de la Universidad literaria de Irache, Pamplona, 1939, aunque sin mucha precisión.

66 Benito RIBAS I CALAF, Annals de Montserrat (1258-1485), Montserrat, 1997, publicado por Xavier Altés; Gregorio de Argaiz, La Perla de Cataluña. Historia de Nra. Sra. de Monserrate, Madrid, 1677; Pedro SERRA Y PosTiUs, Epitome bistórico del portentoso santuario y Real Monasterio de Nuestra Señora de Monserrate, Barcelona, 1747; Miguel MUNTADAS, Montserrat. Su pasado, su presente y su porvenir, Manresa, 1864; Francisco de Paula CRUSELLAS, Nueva bistoria del santuario y monasterio de Nuestra Señora de Montserrat, Barcelona, 1896; Anselmo M. ${ }^{a}$ ALBAREDA-Josep MASSOT I MunTANER, Història de Montserrat, Montserrat, 1977.

67 Gerard Gaillard, Sant Benet de Bages, París, 1959; Fortià Solá Moreta, El monestir de Sant Benet de Bages, Manresa, 1955; Joan PagÈs POns, Les Preses i el monestir de St. Benet de Bages, II, Olot, 1984; Ernesto ZaragoZa Pascual, La unión del monasterio de San Benito de Bages a Montserrat (1594), en Studia Monastica, 24 (1982), pp. 389-394. 
de Fontanes y Sant Feliu de Guíxols ${ }^{68}$; en Castilla la Nueva tenía las abadías madrileñas de San Martín y Montserrat ${ }^{69}$ y la de monjas de San Plácido -éstas dos últimas a partir del siglo XVII-, Ntra. Señora de Sopetrán, en Guadalajara, ${ }^{70}$ y San Benito de Huete, en Cuenca; y sólo una en Andalucía: San Benito de Silos de Sevilla ${ }^{71}$.

Aparte de estas abadías de monjes y monjas de ambas congregaciones claustral y observante, había algunas abadías de monjas dependientes de su respectivo ordinario, como Santa María de las Dueñas de Alba de Tormes y las leonesas de Santa María de Carbajal de León y de Santa Cruz y San Pedro de las Dueñas de Sahagún de Campos; las burgalesas de San Salvador del Moral, San Salvador de Palacios de Benaver y Santa María de Aranda de Duero; Valfermoso de las Monjas (Guadalajara), Santa Ana de Salamanca, Purísima Concepción de Toledo, La Guardia, en Pontevedra, las navarras de San Benito de Estella y San Benito Corella, que luego se fundió con el de San Benito de Calatayud y la navarra de Santa María Magdalena de Lumbier ${ }^{72}$.

También se debe advertir que las abadías de la Congregación de Valladolid, que eran colegio no tenían noviciado y por tanto tampoco profesos propios, salvo algunos pocos para ocupar cargos concretos, como organista, boticario, escri-

68 Alonso CANO, Discurso general de este antiquísimo castillo y monasterio de Sant Feliu de Guíxols, Biblioteca de Montserrat, Ms. 6 (1606); Josep MASSOT I MUNTANER, Els abats de Sant Feliu de Guíxols, en Studia Monastica, XIII (1971), pp. 331-403; Ernesto ZARAGOZA PASCUAL, Abaciologi del monestir de Sant Feliu de Guíxols (segles X-XIX), Col. Scripta et Documenta, núm. 57, Montserrat, 1998.

69 Ernesto Zaragoza Pascual, Historia del real Monasterio de Montserrat de Madrid, en Col. Scripta et Documenta, núm. 51, Montserrat, 1996.

70 Antonio De Heredia, Historia del Ilustrísimo monasterio de Ntra. Sra. de Sopetrán, Madrid, 1676. Véase también lo mucho que hemos publicado de este monasterio en la revista $\mathrm{Wad}-\mathrm{Al}$ Hayara: Ernesto ZARAGOZA PASCUAL. Un abadologio inédito del monasterio de Sopetrán, 3 (1976), pp. 27-46; ID., Los monjes de Sopetrán (1601-1758), 5 (1978), pp. 123-141; ID., Actas de visita del monasterio de Sopetrán (1695-1829), 7 (1980), pp. 59-102; ID., Los abades de Sopetrán (1372-1835), 8 (1981), pp. 435-444; ID., Visitas de fray Diego de Sahagún a los monasterios de Sopetrán, San Millán y Silos (1522-23), 10 (1983), pp. 365-372; ID., Catálogo de monjes profesos de los monasterios de Sopetrán, Sevilla, San Martín y Montserrat de Madrid, 14 (1987), pp. 363-370; ID., Abadologio del monasterio de Ntra. Sra. de Sopetrán (1372-1835), 20 (1993), pp. 222-240; ID., La unión del monasterio de Sopetrán a la Observancia Vallisoletana (1456), 21 (1994), pp. 41-50; ID., Catálogo de los monjes profesos de Sopetrán (1759-1830), 26 (1999), pp. 215-219; ID., Documentos inéditos sobre los últimos benedictinos curas de Torre del Burgo y Heras (1834-1837), 30 (2003), pp. 129-136.

71 Ernesto ZARAGOZA PASCUAL, Abadologio (1503-1835) y Libro de gradas (ss. XVII-XIX) del monasterio de San Benito de Sevilla, en Studia monastica, 39 (1997), pp. 377-402.

72 Mateo DEL ÁlAmo, Congregación de Valladolid, en la Enciclopedia Espasa, vol. 66, Barcelona, 1929, pp. 930-987, aunque ampliamente superado por Ernesto ZARAGOZA PASCUAL, Los Generales de la Congregación de San Benito de Valladolid (1390-1893), 6 vols., Silos, 1973-1987. 
biente, sacristán o hermano lego. Tampoco tenían noviciado propio las abadías menores con menos de doce monjes de comunidad, que dependían de otras abadías mayores, pues todos sus monjes habían tomado el hábito y profesado en la abadía de la cual dependían. Y aunque su superior tuviera el título de abad, éste no era elegido por su comunidad ni en el capítulo general como los demás, sino por el abad y consejo de la abadía de la cual dependía, por eso familiarmente a estas abadía las llamaban abadías manuales o filiaciones. $\mathrm{Y}$ a diferencia de los claustrales no educaban niños en el monasterio, de manera que todas sus vocaciones eran de adultos.

En los monasterios de monjes observantes había cuatro clases de monjes, a saber: monjes de coro, monjes de manto, legos, familiares de hábito largo y de hábito corto. En cuanto a los legos sólo los tenían los grandes monasterios como Montserrat, Sahagún, Oña, San Millán de la Cogolla, Celanova, Samos y San Martín Pinario de Santiago de Compostela, donde eran más numerosos, y los benedictinos claustrales no tenían legos pues preferían servirse de criados seglares, pero a diferencia tenían niños educandos, que servían de monaguillos para el culto litúrgico y eran semillero de vocaciones.

Los abadías de los benedictinos claustrales eran todas sui iuris y algunas tenían parroquias, pero no tenían abadías menores o manuales; sus abades era de elección pontificia, presentados en Roma por el Patronato Real, igual que los oficios llamados claustrales, que era como beneficios, pues como hemos dicho, tenían cada uno sus propias rentas, que ellos administraban. Para ocupar las abadías, los candidatos eran elegidos entre sus propios monjes, pero en los siglos XV y XVI fueron dados en encomienda a clérigos y seculares. Debemos decir que a diferencia de los observantes cuyos cargos abaciales eran trienales en el monasterio de Valladolid y bienales en los demás (1465-1499) y trienales en todos (1500-1610), los abades claustrales eran perpetuos, pero podían ser presentados y elegidos también para ocupar el abadiado de otro monasterio que no fuera el suyo. Asimismo los monjes observantes podían ser trasladados de monasterio a otro por el abad general, no así los claustrales si no era para cumplir algunas penitencias; los cargos de los monasterios observantes eran ad nutum del abad y su consejo, los oficios claustrales de los claustrales en cambio eran casi todos de presentación real y para ocuparlos podían trasladarse de un monasterio a otro, aunque generalmente solían darse a monjes del propio monasterio. Los oficios generales de cada Congregación eran todos elegidos en el capítulo general y duraban hasta la celebración del próximo capítulo general, que era trienal para los claustrales (1215-1835) y también para los observantes hasta 1610, que comenzó a ser cuatrienal hasta 1835. La Congregación observante tenía un abad general, que hasta 1610 era a la vez 
abad del monasterio de Valladolid y elegido por su comunidad y de entre los profesos del monasterio, pero a partir de 1610 era elegido de entre todos los monjes de la Congregación en el capítulo general. Los observantes celebraban siempre el capítulo general en Valladolid, mientras que los claustrales lo celebraban dos seguidos en un monasterio de Cataluña, generalmente en el de Sant Pau del Camp de Barcelona, y el tercero en un monasterio de Aragón, generalmente en Huesca o Graus. La Congregación Claustral en sus capítulos trienales elegía tres abades presidentes, el primero y segundo para su provincia Tarraconense -a proporción del número de monasterios- y el tercero para la provincia Cesaraugustana. Tenían en Lérida un colegio para sus estudiantes catalanes y en el de San Pedro el Viejo de Huesca otro, para los de Aragón y Navarra ${ }^{73}$.

Para seguir con detalle los pasos de la reforma de cada monasterio claustral, que finalmente se integró en la observancia vallisoletana, hay que acudir a nuestra obra: Los Generales de la Congregación de San Benito de Valladolid, vol. I (Silos 1973) y vol. II (Silos 1976) y al abadologio propio de cada monasterio ${ }^{74}$, así como a las

73 Ernesto Zaragoza Pascual, Història de la Congregació Benedictina Claustral Tarraconense y Cesaraugustana, op. cit., $415 \mathrm{pp}$.

74 Ernesto ZaragoZa PasCual Abadologio del monasterio de San Andrés de Espinareda (ss. XI-XIX), en Compostellanum, 60 (2015), pp. 207-237; ID., Abadologio del monasterio de San Pedro de Montes (ss. VII-XIX), ibid., 57 (2012), pp. 279-312; ID., Abadologio del monasterio de San Pedro de Eslonza (ss. X-XIX), ibid., 54 (2009), pp. 217-248; ID., Abadologio del monasterio de San Benito de Sahagún (ss. X-XIX), ibid., 55 (2010), pp. 99-147; ID., Abadologio del monasterio de San Claudio de León (1417-1835), ibid. (en prensa); ID., Abadologio del monasterio de San Vicente de Salamanca (ss. XIII-XIX), en Salmanticensis, LVIII (2012), pp. 291-380; ID., Abadologio (ss. X-XX) y libro de gradas (1614-1830) del monasterio de San Isidro de Dueñas, en Studia monástica (en prensa); ID., Abadologio del monasterio de San Pedro de Villanueva (ss. XII-XIX), en Boletín del Instituto de Estudios Asturianos, 164 (2004), pp. 73-102; ID., Abadologio del monasterio de San Fuan Bta.de Corias (ss. XI-XIX), ibid., núm. 167 (2006), pp. 135-171; ID., Abadologio del monasterio de San Salvador de Celorio (ss. XI-XIX), ibid., 165 (2005), pp. 105-136; ID., Abadologio del monasterio de San Salvador de Cornellana (ss. XII-XIX), ibid., 163 (2004), pp. 165-190; ID., Abadologio de Santa María la Real de Obona (1511-1835), ibid., 141 (1993), pp. 269-299; ID., Abadologio del Imperial Monasterio de Santa María de Obarenes (ss. XII-XIX), en Boletín de la Institución Fernán González, de Burgos (1985), pp. 21-45; ID., Abadologio del monasterio de Ntra. Sra. del Espino (1410-1835), ibid., 206 (1993), pp. 19-36; ID., Abadologio del monasterio de San Pedro de Cardeña (ss. IX-XX), ibid., 207 (1993), pp. 367-397; ID., Abadologio del monasterio de San Pedro de Arlanza (ss. X-XIX), ibid., 210 (1995), pp. 85-109; ID., Abadologio del monasterio de San Zoilo de Carrión de los Condes (ss. XI-XIX) y libro de gradas de los monjes que profesaron en él (1593-1833), en Institución Tello Téllez de Meneses, 64 (1993), pp. 173-321; ID., Abadologio del monasterio de Ntra. Sra. de la Misericordia de Frómista, ibid., 71 (2000), pp. 135-158; ID., Abadologio del monasterio de San Martín de Madrid (1594-1835), en Anales del Instituto de Estudios Madrileños, XXV (1988), pp. 151-179; ID., Abadologio del monasterio de San Salvador de Oña (ss. XI-XIX), en Burgense, 35 (1994), pp. 557-594; ID., Abadologio del monasterio de San Fuan Bta. de Burgos (ss. XI-XIX), en San Lesmes en su tiempo, Burgos, 1997, pp. 345-383; ID., Abadologio del monasterio de Sto. Domingo de Silos (ss. X-XX), Burgos, 1998; ID., 
historias particulares de los que las tengan. Y para obtener más bibliografía de todos los monasterios benedictinos claustrales catalanes, aragoneses y navarros, véase nuestra obra: Catàleg dels monestirs catalans, Col. Scripta et Documenta, vol. 55 (Montserrat 1997) y en el Diccionari d'Història Eclesiàstica de Catalunya, 3 vols. (Barcelona 1998-2000, 2001). Y para todos, las voces de los que aparecen en el Dictionnaire d'Histoire et de Géographie Ecclésiastiques (que llega hasta la letra Lo).

La reforma de los benedictinos claustrales hay que retrotraerla al siglo XV, singularmente después de la guerra de los Remenses pues por causa de la guerra no se pudo celebrar capítulo provincial hasta el 3 de mayo de 1476 en San Benito de Calatayud, donde se prohibió a los monjes la cura de almas fuera del monasterio y por primera vez se nombraron confesores para los monasterios de benedictinas existentes sometidos a la Congregación, a sabe San Daniel de Gerona, Santa Cecilia de Montserrat, San Pedro de les Puel-les, Santa Cruz de la Serós y

Los monasterios benedictinos de la ciudad de Zamora, en Nova et Vetera, 10 (1980), pp. 267-291; ID., Abadologio del monasterio de Ntra. Sra. de la Anunciación de El Bueso (1460-1789), en Investigaciones bistóricas, 21 (2001), pp. 20-45; ID., Abadologio del monasterio de San Benito el Real de Valladolid (1390-1835), en ibid., 23 (2003), pp. 203-260; ID., Abadologio del monasterio de San Benito de Huete (1468-1835), en Studia Silensia, XXV (2003), pp. 499-521; ID., Abadologio (1503-1835) y Libro de gradas (ss. XVII-XIX) del monasterio de San Benito de Sevilla, Studia monastica, 39 (1997), pp. 377-402; ID., Abadologio (ss. X-XIX) y libro de gradas de los monjes (1715-1833) del monasterio de Sta. María la Real de Nájera, ibid., 40 (1998), pp. 121-158; ID., Historia del Real monasterio de Montserrat de Madrid, Col. Scripta et documenta, núm. 51, Montserrat, 1996; ID., Abadologio del monasterio de Ntra. Sra. de Sopetrán (1372-1835), en Wad-Al-Hayara, 20 (1993), pp. $222-$ 240; ID., Abadologio del monasterio de San Martín Pinario (898-1835), en Compostellanum, XXXIX (1994), pp. 209-240; ID., Abadologio del monasterio de San Salvador de Celanova, ibid., 45 (2000), pp. 81-100; ID., Abadologio del monasterio de San Salvador de Lérez (ss. XVI-XIX), en Museo de Pontevedra, 48 (1994), pp. 407-435; ID., Abadologio del monasterio de San Pedro de Tenorio (15431835), ibid., 49 (1995), pp. 267-291; ID., Abadologio del monasterio de San Fuan de Poyo, ibid., 54 (2001), pp. 57-77; ID., Abadologio del monasterio de San Salvador de Lorenzana (1015-1835), en Estudios mindonienses, 11 (1995), pp. 179-203; ID., Abadologio del monasterio de San fulián de Samos (ss. VIII-XX), ibid., 12 (1996), pp. 459-503; ID., Abadologio del monasterio de San Vicente de Oviedo (ss. VII-XIX), en Studium Ovetense, XXVI (1998), pp. 135-165; ID., Abaciologi del monestir de Sant Feliu de Guixols (ss. X-XIX), op. cit.; ID., Abadologio de San Esteban de Ribas de Sil (ss. X-XIX), en Compostellanum, XLVII (2002), pp. 359-399; ID., Abadologio del monasterio de San Fuan Bautista de Poyo (s. XII-XIX), ibid., XLVIII (2003), pp. 391-426 y los abadologios de Montserrat de Cataluña, Sant Benet de Bages y Sant Joan de Fontanes, en mi Abaciologi Benedictí de la Tarraconense, op, cit., pp. 261-304, 54-64, 173-183, respectivamente; ID., Priorologio de Santa María de Piasca (1647-1825), en Altamira, LXI (2004), pp. 229-235; ID., Abadologio y Priorologio de Santo Toribio de Liébana (ss. IX-XIX), en ibid., LXVII (2005), pp. 35-63; ID., Abadologio del monasterio de Santa María la Real de Irache (958-1835), en Leyre, Cuna y Corazón del Reino (Leyre, 2005), pp. 155-204; ID., Abadologio del monasterio de San Bartolomé de Medina del Campo y San Mancio de Rioseco (en prensa). Nótese empero, que cuando hay dos abadologios del mismo monasterio se debe hacer caso al más moderno, puesto que siempre se trata de la revisión y ampliación del antiguo. 
San Benito de Estella ${ }^{75}$. En el capítulo provincial de 1482, se estableció el ritual para recibir las visitas canónicas y la forma de distribuir equitativamente las funciones entre los monjes ${ }^{76}$. No se pudo celebrar capítulo en 1485 en Cataluña por causa de la peste (1483) y de la guerra de los Remenses ${ }^{77}$, que se negaban a pagar los diezmos, intentaron asaltar el monasterio de Santa Maria de Montserrat, expulsaron a los monjes de Breda e intentaron saquear el monasterio de Sant Feliu de Guíxols ${ }^{78}$, hasta que la sentencia real arbitral de Guadalupe del 21 de abril de 1486, que abolió los llamados «malos usos», retornó la paz al país, aunque los monasterios quedaron depauperados en rentas y edificios ${ }^{79}$.

El capítulo provincial celebrado en Sant Pau de Barcelona en 1490 determinó que los monjes no estudiaran fuera de sus monasterios sino que se reunieran todos en uno donde hubiera un maestro de artes. También sabemos que en este mismo año hubo un parlamento general de los abades de Cataluña, en el monasterio gerundense de Sant Pedro de Galligants, seguramente para tratar de las órdenes que los monasterios recibían de parte de los Reyes Católicos para que aceptasen las observancias vallisoletanas. En este parlamento, que tenía la misma autoridad del capítulo general, se mandó a los abades que visitasen sus prioratos. Además, sabemos que a resultas de la última guerra civil, las comunidades habían quedado muy mermadas de monjes, lo que repercutía negativamente tanto en la observancia regular como en el culto litúrgico y la admisión de candidatos no bien preparados o sin verdadera vocación monástica. Así el monasterio de Galligants, en 1492, sólo tenía cuatro monjes ${ }^{80}$ y el gran santuario de Montserrat tenía sólo siete, tres ermitaños, dos donados, dos escolanes y un lego. Y así, el mismo abad de Montserrat, Juan de Peralta, en 1490 para remediar la situación, envió al Rey Católico al ermitaño de la misma montaña y antiguo secretario real, Bernardo Boïl, para que el monarca apoyase la petición que había hecho al monasterio italiano de Santa Justina de Padua de que enviase algunos monjes para reformar Montserrat, pero recordando el fracasado intento habido treinta años

75 Archivo de la Abadía de Montserrat (Barcelona), Fondo Claustral I (I= a libros) en adelante (AAM, CI), vol. 5, pp. 130-141, 150-153.

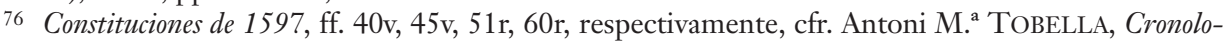
gia dels capitols de la Congregació Claustral Tarraconense i Cesaraugustana (1219-1661), en Analecta Montserratensia, vol. X, Montserrat, 1964, p. 272.

77 Francisco MONSALVATJE Y Fossas, Noticias históricas, vol. XIII, Olot, 1906, pp. 154, 390; Jaime VILlanUEVA, Viage literario a las iglesias de España, vol. XIV, Madrid, Imp. RAH, 1850, p. 53.

78 José Pella y Forgas, Historia del Ampurdán, Barcelona, 1883,Anastática, Olot, 1980, p. 695.

79 Francisco MONSALVATJE Y Fossas, Noticias históricas, vol. XIII, Olot, 1903, pp. 158.

80 Josep CalZada Oliveras, Sant Pere de Galligans, Girona, 1982, p.74. 
atrás, no accedió a su petición. Fue entonces cuando el mismo abad pidió el envío de monjes observantes valllisoletanos, los cuales finalmente aceptaron implantar su observancia en Montserrat, con la condición de que el monasterio había de quedar sujeto al prior de San Benito de Valladolid. Para ello, los Reyes Católicos obtuvieron una bula del papa Alejandro VI el 19 de marzo de 1493 por la cual el monasterio de Montserrat aceptaba las observancias vallisoletanas, incluida la del voto de clausura perpetua -exclusivo de los vallisoletanos-, sería gobernado como los otros monasterios observantes por un prior bienal -fuera del de Valladolid, que era trienal- y permanecería perpetuamente unido a la Congregación de Valladolid. Pero como sólo tres monjes de la comunidad montserratina aceptaron este acuerdo, fueron enviados desde Valladolid una docena de monjes observantes, acompañados de su prior general fray Juan de San Juan de Luz, que nombró como primer prior bienal al subprior de Valladolid, fray García Jiménez de Cisneros, el 28 de junio de 1493, perdiéndose este gran monasterio y santuario para la Congregación Claustral ${ }^{81}$. Pocos meses después los claustrales tuvieron un parlamento para tratar sobre el paso del monasterio de Montserrat a la Congregación de Valladolid y sobre las presiones que otros monasterios recibía para hacer lo mismo.

También en el mismo año de 1493, la Reina Católica aconsejó a la comunidad de monjes claustrales de Valvanera, en la Rioja, que aceptase la reforma vallisoletana, cosa que prometió su abad D. Pedro Fernández de Anguiano al tomar posesión de aquel monasterio en 1495, aunque disconforme con algunas de las normas de los observantes, difirió sine die la unión del monasterio a la Observancia de Valladolid ${ }^{82}$.

Por lo que respecta a la visita y reforma de todas las monjas del Principado de Cataluña, los Reyes Católicos -con licencia apostólica- el 4 de noviembre de 1493 nombraron visitadores generales a D. Juan Daza, deán de Jaén, y al franciscano fray Miguel Fenals ${ }^{83}$, los cuales no fueron aceptados por los monjes claustrales, sin duda por no ser miembros de la propia Orden. Por eso desde Zaragoza, la Reina Católica, el 11 de diciembre de 1493 y el Rey Católico el 20 del mismo mes y año, confirmaron su apoyo a los dichos visitadores, mandándoles que en:

81 Ernesto Zaragoza Pascual, Los Generales, op. cit., vol. I, Silos, 1973, pp. 202-203; Anselmo M. ${ }^{a}$ AlbaredA-Josep MASSOT i MunTANER, Història de Montserrat, op. cit., pp.71-72.

82 Ernesto Zaragoza Pascual, Los generales, op. cit., II, Silos, 1976, p. 110.

83 Archivo de la Corona de Aragón, en Barcelona, Sec. de Monacales de Hacienda, Registro (en adelante: ACA, MH, Reg.) 3611, ff. 21r-22r, cfr. José GARCÍA ORO, La reforma de los religiosos españoles en tiempo de los Reyes Católicos, Valladolid, 1969, pp. 247-248. 
«quanto a lo que dezís de la abadesa de San Pedro, devéys continuar vuestro proceso fasta la privación, y en tenerlo ansy fecho, fazérnoslo saber ${ }^{84}$. El mismo Rey Católico manifiesta a su Lugarteniente General de Cataluña, en carta fechada en Medina del Campo el 10 de marzo de 1494, que sabe que: «a consejo de Micer Ribalter, la abadesa y monjas [benedictinas] de San Pedro [de las Puel.les] y [las cistercienses] de Valldoncella perseveran en su dureza e obstinación, e no quieren obedescer a los dichos visitadores, ni cumplir sus provisiones, y dice que han dicho palabras muy escandalosas y injuriosas contra los dichos visitadores, $\mathrm{y}$ en denegación de nuestras preheminencias reales, a fin de exitar al pueblo contra ellos en grande deservicio de Dios y nuestro». Por eso os mando «que ayudeys y favorezcays a los dichos visitadores en todas las cosas de su oficio» ${ }^{85}$, los cuales, efectivamente, decidieron aquel mismo mes «dar principio a la obra para la clausura de San Pedro e de Valldonçella» ${ }^{86}$. El punto que más denostaban las monjas era la implantación de la estricta clausura con torno, hasta el punto que la Reina Católica, el 10 de marzo de 1494 escribió a los visitadores que no les pusieran torno, puesto que había otras monjas reformadas que no lo tenían ${ }^{87}$. No obstante, los mismo reyes Católicos, en otra carta del 23 del mismo mes, dicen a los visitadores:

Nos parece que en San Pedro se deve poner torno, y aunque vos hovimos scripto que no se devía poner en el dicho monesterio, agora que havemos sabido que lo tienen las otras de la misma religión, nos parece que es bien que se ponga en él... salvo si a vosotros otra cosa paresçiere; lo que fizierdes tendremos por bueno... Quanto a lo otro que dezís de la abadesa de San Pedro, vos dezimos, que si está de continuo en rebeldía y contumacia, la devéys privar y encomendar la administración a una monja del mismo monesterio, que paresciere más hábile para ello fasta tanto se provea el abadesa...y también la forma que ternà en el regimiento la monja a quien encomendáredes la administración, porque si fuere tal qual deve, se le dé el abadiadgo ${ }^{88}$.

Pero las monjas de San Pedro apelaron al Papa. Lo sabemos porque luego micer Ribalter se ofreció a solucionar este asunto, escribiendo al Rey Católico, que si los visitadores le permiten «entrar en el monasterio de San Pedro, él ternà

\footnotetext{
84 ACA, MH, Reg. 3611, ff. 28r; ibid., ff. 39r-40v, cfr. José GARCÍA ORO, op. cit., pp. $259,272$.

85 ACA, MH, Reg. 3611, ff. 40r-v, cfr. José GARCÍA ORO, op. cit., p. 269.

86 ACA, MH, Reg. 3611, ff. 39v, cfr. José GARCía ORO, op. cit., p. 271.

87 ACA, MH, Reg. 3611, ff. 44r-v, cfr. José GARCÍA ORO, op. cit., p. 276.

88 ACA, MH, Reg. 3611, ff. 61r, cfr. José GARCÍA ORO, op. cit., p. 285.
} 
manera con la abadesa y monjas que desistan y se aparten de la apelación y interposición para nuestro muy sancto Padre», pero el monarca, el 4 de junio del mismo año 1494, deja esta decisión al criterio del visitador Daza ${ }^{89}$.

Pero los visitadores depusieron a la abadesa Dña. Constanza de Peguera y la recluyeron en casa de un hermano suyo, de donde los Reyes en carta del 18 de octubre del mismo año, mandan a los visitadores que la lleven interinamente al monasterio de Montesión, al tiempo que en la misma fecha escriben a su embajador en Roma, el obispo de Badajoz: «que las monjas de San Pedro y de algunos otros monasterios de la ciudad quedan muy enojadas y descontentas por haberles quitado aquella tanta profanación en que contra Dios e su regla vivían», y que pida al Papa que las apelaciones de dichas monjas sean remitidas al arzobispo de Mesina y al obispo de Catania ${ }^{90}$. También mandó al arzobispo de Mesina, que revisara la sentencia de deposición de la abadesa de San Pedro ${ }^{91}$. Finalmente, para reformar la comunidad de monjas de San Pedro se acordó enviar allí benedictinas reformadas - pero no sometidas a la Congregación de Valladolid- que el propio Rey Católico pidió al obispo de Burgos, a saber: Isabel Manuel, priora del monasterio de Tórtoles de Esgueva, y cuatro monjas más de otros monasterios burgaleses, tal como lo comunican los Reyes Católicos en carta del 15 de febrero de 1495 a las monjas de San Pedro, pidiéndoles que las reciban con caridad ${ }^{92}$.

En el mismo año de 1495 el abad del monasterio de San Millán de la Cogolla, entonces perteneciente a la Congregación Claustral, Pedro Sánchez del Castillo trataba con el prior de Valladolid de la reforma de su monasterio, como lo dice él mismo en una carta del 15 de junio de 1498, si bien no se reformaría hasta $1501^{93}$.

En el capítulo provincial de 1496 ante el apremiante deseo de los Reyes Católicos de que los monasterios benedictinos se reformasen, se dieron ciertas normas para enderezar la vida comunitaria, entre ellas que los monjes comiesen en el refectorio tres días a la semana durante el Adviento y la Cuaresma, y que los abades no dieran permiso a sus monjes para salir del monasterio, fuera del caso de necesidad, sólo por el tiempo que faltaba para la próxima hora canónica y siempre dejando el número suficiente de monjes para la celebración del Oficio Divino y

\footnotetext{
89 ACA, MH, Reg. 3611, ff. 74r, 90v, cfr. José GARCÍA ORO, op. cit., pp. 288-289, 307.

90 ACA, MH, Reg. 3811, ff. 89r-v, 90r-v, cfr. José GARCÍA ORO, op. cit., pp. 309, 311-312, 315.

91 ACA, MH, Reg. 3611, ff. 30r-v; Reg. 3811, ff. 92v-93.

92 ACA, MH, Reg. 3006, ff. 203r-222r.

93 Ernesto Zaragoza Pascual, Los generales, op. cit., vol. I, p. 184.
} 
no podían comer fuera del monasterio sin permiso del abad y que se observaran las constituciones: Et quia secundum Gregorium i Saluti animarum ${ }^{94}$.

Así acaba el siglo XV, la segunda mitad del cual está marcada por los intentos de reforma observante por parte de los Reyes Católicos, aunque su culminación no llegaría hasta finales del siglo XVI.

$\mathrm{Al}$ primer capítulo provincial claustral celebrado en Sant Pau del Camp de Barcelona en 1500, no asistieron los abades de Aragón y de Navarra, sin duda porque como los demás, desde 1493 se trataba de que aceptaran las observancias vallisoletanas. Sabemos que este capítulo promulgó dos constituciones que interesaban a la reforma de la observancia, una sobre el dormitorio común y otra sobre el destino de los monjes trasladados a otros monasterios, sin duda por no aceptar la implantación de la observancia vallisoletana en los suyos ${ }^{95}$.

Del capítulo de 1503 celebrado en Sant Pau del 3 al 13 de mayo, no tenemos las visitas de los monasterios de aquel trienio, pero sí las actas del capítulo, examinadas las cuales vemos lo que se había de reformar en la vida comunitaria, especialmente en aquellos monasterios que tenía abades comendatarios, siempre ausentes, que confiaban la comunidad a un vicario general. Por eso el capítulo acordó que no pudieran ser nombrados vicarios generales sino monjes de la propia Congregación Claustral, tal como se había acordado ya en el capítulo de 1482 . Y como se les echaba encima la visita de los visitadores vallisoletanos, que ellos llaman «intrusos», se determinó que los dos abades presidentes y dos monjes elegidos por ellos, nombraron a los abades de Guíxols y de Colera in solidum como comisarios permanentes para tratar los asuntos de reforma que surgiesen hasta el próximo capítulo provincial, determinando hacer un repartimiento para los gastos de la visita apostólica, en realidad para defender la Congregación Claustral de las pretensiones y reforma radical encaminada a suprimir la observancia claustral y finalmente la misma Congregación. Por eso determinaron luchar para defender su forma secular de entender y vivir la regla de san Benito y de gobernarse según las normas de la bula Summi Magistri y así conservar su independencia. Pero si los deseos de reforma regular manifestados en los capítulos y en las visitas canónicas no tuvieron éxito, fue porque muchas comunidades no tenían abad regular residente, sino comendatario, pocos monjes y pocas rentas. Los oficiales vivían dentro de los muros del monasterio, pero cada uno en la casa de su oficio y viviendo de las rentas de su cargo, de manera individual.

\footnotetext{
94 Antoni M. ${ }^{\text {a }}$ TOBElla, op. cit., p. 277.

95 AAM, CI, vol. 8, ff. 1-7 (acta capitular).
} 
En estos años se dieron pasos al parecer dirigidos a la supresión de la Congregación Claustral, además de que los abades de la provincia Cesaraugustana (Aragón y Navarra) hacia ya más de un decenio que no acudían a los capítulos provinciales, el monasterio de Valvanera iban a consolidar su pertenencia definitiva a la Congregación de Valladolid, igual que el de San Millán de la Cogolla, que había sido reformado a fines de 1500 con catorce monjes observantes y su abad Pedro Sánchez del Castillo había renunciado a su abadía en manos del Papa. $\mathrm{Y}$ aunque los observantes fueron expulsados del monasterio, con ayuda de los Reyes Católicos retornaron a él en 1501 y fue unido definitivamente a Valladolid por bula del 15 de mayo de $1502^{96}$.

Es más, el Rey Católico desde Llerena, el 11 de marzo de 1500, escribía a su embajador en Roma, Francisco de Rojas:

Teniendo mucha voluntad que los monesterios de San Benito de los mis reynos de Aragón sean puestos en verdadera reformaçión e observançia...vos encargo y mando que en virtud de la creencia que en la presente vos envío para Su Santidad, sypliquéys luego de mi parte con mucha instancia le plega por su decreto apostólico cometer al abbad de Nuestra Señora de Montserrat e a micer Jaime Reglá, deán de Barcelona, al prior de Santana de la dicha ciudad, e a cada uno dellos, que por cessim o decessim del abad que oy es del monesterio de San Cugat e renunciando el arçobispo mi fijo la coadjutoria e regreso que allí tiene, reformen el dicho monesterio le pongan en observancia regular e reduzcan al trienio, según e de la manera que se fizo en el de Montserrat y que las pobordías e otros qualesquier beneficios del dicho monesterio de San Cugat que de presente poseen monjes o clérigos in commendam sean extintos, e la renta dellos incorporada al cuerpo de dicho monesterio ${ }^{97}$.

Todavía el 31 de julio de 1503 en una instrucción a su embajador, Fernando el Católico le manda obtener del Papa la reducción del abadiato al trienio de la abadía de Sant Cugat del Vallès, añadiendo: «e trabajad para que los monesterios de Ripoll i Arles se den para el trienio, según que diversas vezes os lo havemos escrito» ${ }^{98}$.

Así, el abad de Montserrat, fray García Jiménez de Cisneros, fue nombrado reformador apostólico de los monasterios claustrales, como subdelegado de Fadrique de Portugal, abad comendatario de Ripoll y obispo de Calahorra, visitador de los benedictinos, juntamente con los obispos de Burgos, Palencia y Àvila, en

\footnotetext{
96 Ernesto Zaragoza Pascual, Los generales, op. cit., II, Silos, 1976, p. 42.

97 ACA, MH, Reg. 3670, f. 3r, cfr. José GARCía Oro, op. cit., Doc. 243.

98 AHN, Sec. de Clero, Leg. 7735.
} 
substitución del arzobispo de Messina i de los obispos de Coria y Catania. De hecho sabemos que visitó Ripoll en el verano de $1503^{99}$, y también los monasterios de Guíxols, Arles, Sant Genís de Fontanes y Sant Cugat del Vallès, donde implantó la observancia vallisoletana, obligando a los monjes que no quisieron aceptarla a abandonar su monasterio y recluirse en alguno de sus prioratos. Pero las dificultades y resistencia fueron tan fuertes, que pronto se desengañaron de poder implantar la reforma vallisoletana, comenzando porque los abades que eran bendecidos y perpetuos, fueran solo trienales. Así pidieron al papa que las abadías fueran proveídas en monjes observantes que implantasen la reforma de vida y la bolsa común, suprimiendo los oficios claustrales, a medidas que fueran vacando. Así lo escribió a Fernando I su embajador en Roma, D. Francisco de Rojas, en carta escrita en Barcelona el 31 de julio de 1503:

Diversas vezes os hemos escrito... que procurásedes con nuestro muy santo padre le pluguiese conçeder por sus bullas apostólicas que todos los monasterios de la Orden de Sant Benito que son en todos nuestros reynos e señoríos fuesen reformados y puestos en observançia regular y reduzidos al trienio como lo está el monasterio de Sant Benito de Valladolid y los otros de su Congregaçión... entre los quales señaladamente dezíamos que procurásedes que se diesen a la dicha Congregaçión para que se reformasen los monasterios de Ripoll y Arles, que son en este principado de Cataluña, pero porque podría ser que Su Santidad no lo conçediese ansí como lo demandamos, y nos paresçe que, quando más no se pudiese hazer, será muy mejor poner estas abadías en poder de personas religiosas observantes de la dicha orden, que de presente las reformen y quando tiempo más oportuno se ofreçiere las dexen libremente para las reduzir al triennio, que dexarlas perder y venir en manos de comendatarios, acordamos... quando del todo las desauziásedes, que no se podían obtener las bullas de la reformaçión al trienio, y en tal caso suplicaréys a Su Santidad le plega proveer de la abadía de Ripoll a fray Martín de León y de la de Arles a fray Pedro de Burgos, ambos monjes de Montserrat, y trabajad tanto quanto pudiéredes que las bullas sean expedidas en favor de la reformaçión observançia e comunidad, y que sean extinguidos los beneficios y pabordías conventuales, asi como vacaren ${ }^{100}$.

En Sant Cugat, Cisneros obligó a los monjes a aceptar la observancia vallisoletana y los que no quisieron aceptarla, abandonaron el monasterio y se fueron a vivir a la casa procura del mismo monasterio situada en Barcelona, en la cual se reunieron los abades presidentes de la Congregación el 4 de agosto de 1504 y de-

99 Gregorio de Argaiz, La perla de Cataluña, op. cit., p. 132; M. NAVARro, Biografía de García de Cisneros, que precede a su Exercitatorio de la Vida Spiritual, Salamanca, 1712, p. 85.

100 AHN, Clero, Leg. 7735. 
terminaron enviar a Miquel Ros a Roma para defender sus derechos ${ }^{101}$. Tambien el abad Cisneros envió a Roma a fray Pedro de Burgos -que luego le sucedería en el abadiato de Montserrat-, pero al fin se firmó una concordia entre los reformadores y los claustrales en $1506^{102}$.

Cisneros había sido nombrado visitador apostólico de todos los monasterios de España por Alejandro VI en 1505, juntamente con el obispo de Ávila, pero de hecho sólo visitó los de la Congregación Claustral Tarraconense y Cesaraugustana, igualmente que su successor fray Pedro de Burgos, aunque el fruto de esta visita fue muy poco y efímero. Quedó reducido a la anexión a Montserrat en 1504 del monasterio de Santa Cecilia sito en la misma montaña, a la muerte de su abad comendatario Jaime Filella, deán de la catedral de Barcelona, aunque el monasterio era habitado por sólo dos monjes y los edificios estaban en muy mal estado.

El comendatario de Ripoll renunció a la abadía a favor de García de Cisneros en 1508 para que fuera su primer abad trienal, pero el papa Julio II dio la abadía en encomienda al cardenal de San Clemente, Jaime Serra ${ }^{103}$. Y como sin el abadiato trienal y la vida y economía comunitarias no se podía reformar el monasterio en profundidad, según el estilo de la Observancia, la visita apostólica y con ella la reforma introducida quedó sin efecto, excepto algunos puntos de importancia secundaria. El mismo abad presidente claustral Galcerán de Rocabruna, acompañado del cillerizo de Roda, fue a Segovia, donde se hallaba Fernando el Católico, para pedirle que la reforma se hiciera en el próximo capítulo general de 1506 al que asistiría el abad Cisneros, cosa que les fue otorgada ${ }^{104}$.

Al capítulo provincial de 1506 celebrado en Sant Pau del Camp el 18 de octubre, asistió Cisneros, que expuso un plan de mínimos de reforma para los monasterios claustrales ${ }^{105}$, a partir del cual el capítulo promulgó quince constituciones que afectaban a la reforma de las costumbres, al culto divino y a las limosnas. Instauran la celebración diaria del capítulo de culpas conventual; la recepción al menos mensual de los sacramentos de la confesión y comunión; establecen que cada monasterio tenga el número de monjes reglamentario, que todos duerman en un dormitorio común y coman en el refectorio y con lectura, tratan también

101 AAM, CI, vol. 9, pp. 173-174; M. NAVARRO, op. cit., pp.84-85.

102 García M. ${ }^{a}$ Colombàs, Un reformador benedictino en tiempo de los Reyes Católicos, Montserrat, 1955, p. 349; Gregorio de ARGAIZ, op. cit., p. 132 dice que fue en 1505.

103 Ernesto Zaragoza Pascual, Abaciologi Benedictí de la Tarraconense, op. cit., p. 337.

104 Alonso CANO, op. cit., f. 162r.

105 García M. ${ }^{a}$ COLOMBÀs, op. cit., pp.349-372; J. M. BESSE, La congrégation bénédictine espagnole dite des Claustrales, en Papauté, monachisme et théories politiques, Lyon, 1994, pp. 284-285. 
de la distribución de la comida y del vestuario personal, del hábito y de la tonsura, restringen los permisos para salir del monasterio, prohibien los juegos de cartas, regulan los oficios de portero y las horas en que se han de cerrar las puertas, mandan que no se pongan de luto por la muerte de sus familiares cercanos, que no se admitan mujeres dentro de las oficinas regulares, que se dé una moderada retribución de los visitadores y renuevan bajo diversas penas el cumplimiento de las otras constituciones aprobadas en los capítulos anteriores ${ }^{106}$. En una palabra se aceptaba la vida comunitaria de la regla benedictina (en el refectorio, coro y dormitorio), la separación del mundo (guardar la clausura, y minorar las salidas) y la pobreza (vestuario, hábito, juego y limosnas). Precisamente estos eran los tres puntos principales de la reforma propuesta por el abad Cisneros ${ }^{107}$. Como fruto de la reforma fue unido a Montserrat el monasterio de Sant Genís de Fontanes el 11 de agosto de $1507^{108}$.

Mientras el abad Cisneros pasaba la visita apostólica a los monasterios catalanes y a petición suya, el 21 de enero de 1509, el rey Católico «maravillado» escribió una carta al abad de Valvanera, Pedro Fernández de Anguiano, porque, aunque el 20 de enero de 1497 se habían reunido las rentas de la mensa abacial y la mensa conventual, todavía no habían admitido la reforma, diciéndole: «Yo vos ruego e encargo se faga luego la dicha reforma» ${ }^{109}$. Al tiempo que mandaba a Cisneros que: «dexéis en la dicha casa por sus días al dicho abbad y assimismo a los monjes que en ella residen, que de su voluntad quisieren quedar so la dicha vuestra obediencia. $\mathrm{Y}$ en lo que toca al modo de vivir de aquí adelante, tengáis respecto al lugar do la dicha casa está fundada y a la poca renta que tiene» ${ }^{110}$. Así en febrero de 1509 Cisneros, acompañado de fray Pedro de Burgos, visitó el monasterio de Valvanera, donde a pesar de la oposición del abad y del obispo de Calahorra, implantó la reforma, después de firmar una concordia con el abad, por la cual éste podía continuar ostentando el título de abad y vivir en el monasterio, sin vestir el hábito de los observantes y con dos monjes para que le sirviesen. Pactando que en caso de que renunciara a la abadía que se le darían las rentas de los prioratos de Anguiano y de Arenzana de Abajo, una viña en Sendero y 13.000 maravedís sobre las alcabalas de Santo Domingo de la Calzada, además del servi-

\footnotetext{
106 Constituciones de 1582; Constituciones de 1597, cfr. Antoni M. ${ }^{a}$ Tobella, op. cit., p. 282.

107 AAM, CI, vol. 4, núm. 4.

108 Anselmo M. ${ }^{a}$ Albareda-Josep Massot i MunTaner, op. cit., pp. 75-76.

109 Archivo de la Congregación de Valladolid, en el monasterio de Silos, Documentación Varia, vol. II, ff. 41r-42r (copia simple).

110 Ernesto Zaragoza Pascual, Los Generales, op. cit., vol. II, p. 111.
} 
cio de mesa y misa y el priorato de Soria. Pero no renunció a la abadía hasta 1523. Y así, según la costumbre de los observantes, para el gobierno de la comunidad nombró como presidente a fray Domingo Sobrarías ${ }^{111}$.

Cisneros en marzo de 1508 visitó el monasterio de Sant Feliu de Guíxols, donde la comunidad aceptó las observancias vallisoletanas y eligió abad a Juan Nadal, que envió a Burgos al monje Gabriel Castany para pedir al Rey Católico el alzamiento del secuestro de las rentas del monasterio, cosa que le otorgó el monarca el 8 de mayo del mismo año ${ }^{112}$. Y el 12 de octubre siguiente, desde Córdoba, el monarca escribía a su embajador en Roma mandándole que obtuviera del Papa la anulación de la colación que había hecho de esta abadía al Cardenal de Santa Pudenciana y alcanzara la confirmación de Nadal, pero como abad trienal, como lo eran todos los de la Congregación Casinense, cuya observancia guardaba el monasterio desde hacía algunos años ${ }^{113}$. En efecto, el cardenal renunció a la abadía el 11 de enero de 1509 a cambio de una pensión vitalicia, y lo mismo hizo el clérigo Rebolledo que la tenía en expectativa, a cambio de 100 ducados ${ }^{114}$.

En 1510 murió el abad Cisneros y el papa León X nombró visitador apostólico a su sucesor en Montserrat fray Pedro Muñoz, pero por poco tiempo, porque en 1512 renunció a la abadía, sin que sepamos la causa ${ }^{115}$.

Por su parte el abad de San Millán, Miguel de Alzaga, obtuvo del papa Julio II el 22 de marzo de 1510 una bula por la cual el monasterio emilianense ya reformado y unido a la Congregación de Valladolid, volvería a formar parte de la Congregación Claustral Tarraconense y su abad a ser perpetuo. Pero apenas publicada la bula, el abad de Valladolid acudió a San Millán, acompañado del

111 AHN, Clero, Leg. 3182 (copia simple de la concordia); Ernesto ZARAGOZA PASCUAL, Abadologio de Valvanera, op. cit., p. 347.

112 ACA, MH, Reg. 3580, ff. 69r, 100r; Ernesto ZaragOZa PASCUAL, Abaciologi del monestir de Sant Feliu de Guíxols, op. cit., p. 28.

113 AHN, Sección de Estado, Leg. 8714, núm. 3 (original); Ernesto ZARAGOZA PASCUAL, Abaciologi del monestir de Sant Feliu de Guíxols, op. cit., p. 29; ID., La observancia casinense en Cataluña (14351523), en Analecta Sacra Tarraconensia, 61-62 (1989), pp. 333-360.

114 Archivo de la Congregación de Valladolid, en el monasterio de Silos, Documentación Varia, vol. XXXVI, f. 455v; Biblioteca Nacional de Madrid, Ms. 3532, f. 43r.

115 Archivo del monasterio de Sant Pere de les Puel.les, Manual del notari foan Faner, vol. 41, f. 159r; Antonio de YePEs, Corónica general de la Orden de San Benito, vol. IV, Valladolid, 1612, f. 214r; Gregorio de ARGAIZ, La perla de Cataluña, op. cit., pp. 141-142, 147, 161-164; Benito TRISTANY, Corona benedictina adornada de lo más precioso de sus singulares prerrogativas con el esmalte de la jurisdicción ordinaria que pueden exercer los presidentes de la Muy Noble y Esclarecida Congregación Claustral de San Benito en la Provincia Tarraconense, Cesaraugustana y obispado de Mallorca, Barcelona, 1677, pp. 5-57. 
licenciado Francisco Galindo y del escribiente Antonio del Corral, aunque no se le permitió la entrada, porque Pedro de la Cueva les aseguró que guardaba el monasterio en nombre de Juana de Aragón, esposa del Condestable de Castilla. Pero el 18 de octubre de 1510 de noche, huyó del monasterio el abad Alzaga, en espera de que en Roma defendiesen su derecho a la perpetuidad abacial. Pero el licenciado Galindo hizo publicar un bando mandando: «a qualquiera que supiere o oviere oído decir dónde y en qué parte estaban fray Miguel de Alzaga e fray Andrés de Negueruela, que luego me lo vengan a decir so pena de muerte» ${ }^{116}$. Pero tras diez meses de incógnito en Navarra, el abad fue descubierto por traición de un clérigo, y el 25 de julio de 1511 fue alanceado cerca de Aguilar por haber ganado una sentencia contra el Duque de Nájera, que fue quien le hizo matar. Luego a petición del Rey Católico, el papa Julio II con fecha del 1 de setiembre de 1512 mandó que el monasterio de San Millán retornara a la Congregación de Valladolid, de la cual ya no se separaría jamás ${ }^{117}$.

Del 3 al 7 de mayo de 1512 se celebró capítulo provincial en Sant Pere de Galligants ${ }^{118}$, que renovó la prohibión de los juegos de naipes y mandó que antes de acabar el año todos los monasterios tuvieran un libro donde se recogieran las constituciones de la bula Benedictina y de los capítulos provinciales y que hubiera un archivo común de la Congregación Claustral, en el monasterio de benedictinas de San Daniel de Gerona, donde se guardasen las constituciones, la visitas, los libros de cuentas y las actas de los capítulos provinciales y la caja común de la Congregación ${ }^{119}$.

Poco después se encargó la visita a todos los religiosos de Aragón al cartujo obispo de Tortosa, Luís Mercader, que el 1 de setiembre de 1514 subdelegó para los benedictinos en el abad de Valladolid, fray Pedro de Nájera ${ }^{120}$.

Los monjes del monasterio de Sant Feliu de Guíxols, el 11 de mayo de 1510 aceptaron ser visitados por los abades de Montserrat, cosa que confirmó el papa Julio II el 6 de febrero de $1512^{121}$. Pero la Congregación Claustral apeló a Roma para evitar la ejecución de la bula y visitó el monasterio del 6 al 8 de marzo del

${ }^{116}$ Joaquín PEÑA, op. cit., p. 196.

117 Gregorio de ARGaIZ, La soledad laureada por San Benito y sus bijos, op. cit., vol. VI, Madrid, 1675, p. 491; Joaquín PEÑA, op. cit., pp. 196-197; AHN, Clero, Leg. 2288, Cód. 898-B; Antonio de YEPES, op. cit., vol. I, Irache 1609, f. 282r; Ernesto ZARAGOZA PASCUAL, Los Generales, op. cit., vol. II, pp. $42-43$.

118 AM, CI, vol. 10, f. 62 r.

119 AM, CI, vol. 10, ff. 62r-70v, cfr. también Antoni M. ${ }^{\text {a }}$ ToBELLA, op. cit., pp. 284-285.

${ }^{120}$ José GARCÍa ORO, op. cit., p. 413.

121 Alonso CANO, op. cit., ff. 161v-162r, aunque dice equivocadamente que fue en 1513. 
mismo año ${ }^{122}$. Pero el abad Nadal acudió al Rey Católico y éste mandó al abad de Montserrat, fray Pedro Muñoz que «porque la dicha visitaçión toca agora a vos, como abad de esta devota casa de Monserrate, rogamos e encargamos que luego vais personalmente al dicho monesterio de San Felio de Guíxoles y ayuntado el abbad y monjes les presentaréis el dicho breve en virtud del qual visitaréis el dicho monesterio...i advertiréis que se haga con tal templanza y poco a poco, de manera que los religiosos no se escandalizen...También escribimos al dicho P. Abad y convento la letra que será con ésta, recordándole la palabra que de ellos tenemos, porque obedezcan la visitación» ${ }^{123}$. Así pues, el abad Muñoz visitó el monasterio guixolense el 27 de junio y permitió a los monjes continuar vistiendo el hábito y seguir las ceremonias casinenses ${ }^{124}$. El Rey Católico, el 13 de junio de 1513 obtuvo de Roma para fray Pedro de Burgos, abad de Montserrat, el nombramiento de visitador apostólico para todo los monasterios de benedictinos y benedictinas de Cataluña.

Por este tiempo las benedictinas del monasterio de San Antón y Santa Clara de Barcelona, se negaron a recibir los visitadores franciscanos claustrales, que sin duda quería recuperar para su orden el monasterio que hacía más de un siglo había aceptado la regla benedictina. Acudieron las monjas al Papa, que había nombrado jueces delegados suyos para esclarecer la verdad, a los canónigos barceloneses Mn. Feilla y Mn. Joan Busquets. Pero las monjas claustrales no reconocieron como visitador suyo al abad observante de Montserrat, fray Pedro de Burgos. Por eso el Rey Católico el 31 de julio de 1513 comisionó al dicho abad, que visitara por si mismo o por un delegado suyo aquel monasterio, al tiempo que le dice que escribe a los mencionados canónigos jueces y a la abadesa del monasterio para que le obedezcan en todo ${ }^{125}$. Y con eso las monjas aceptaron las observancias vallisoletanas ${ }^{126}$. Sabemos también que fray Pedro visitó otros monasterios benedictinos de Cataluña, pues el mismo monarca, con fecha del 23 de diciembre de 1513 tomó bajo su protección el monasterio de Guíxols, al tiempo que pidió a León X, que confirmase la bula de Julio II $^{127}(1513)$ que hacía visitadores del monasterio a los abades de Montserrat y prohibía a los claustrales

\footnotetext{
122 Ernesto Zaragoza Pascual, Abaciologi del monestir de Sant Feliu de Guíxols, op. cit., p. 29.

123 Cfr. Ernesto Zaragoza Pascual, Los Generales, op. cit., vol. II, p. 172.

124 Gregorio de ARGAIZ, La perla de Cataluña, op. cit., pp. 141-142.

125 ACA, MH, Reg. 3677, ff. 65v-67v, cfr. José GARCÍA ORO, op. cit., pp. 411-412.

126 Tarsicio de AzCONA, Paso del monasterio de Santa Clara de Barcelona a la regla benedictina (1512-18), en Collectanea franciscana, núm. 38 (1968) pp. 78-134; Ernesto ZARAGOZA PASCUAL, Abaciologi Benedictí de la Tarraconense, op. cit., p. 267.

127 Ernesto ZaragoZa PasCUal, Abaciologi del monestir de Sant Feliu de Guixols, op. cit., p. 30.
} 
visitar dicho monasterio, como lo concedió el pontífice el 7 de abril de 1514, a solicitud también del obispo de Gerona, Guillem Ramón Boíl, que la ejecutó el 15 de febrero de 1515, a pesar de que la Congregación Claustral no sólo apeló de ella a Roma, sino que celebró, tal como estaba previsto desde 1512, en el monasterio su capítulo provincial del 3 al 6 de mayo de $1515^{128}$, en el cual se urgió a los abades morosos que pagasen lo que les correspondía para el sustento del Estudio General de Banyoles ${ }^{129}$, se prohibió la admisión al hábito de hijos ilegítimos y se declaró que la autoridad de los visitadores era la misma que la de los abades presidentes de la Congregación ${ }^{130}$.

Por otra parte, sabemos que en 1515, a petición del infante Enrique de Aragón, conde de Ampurias, el papa León X había expedido un breve comisionando a fray Pedro de Burgos la visita apostólica de los monasterios benedictinos de su Condado, a saber: Roda, Roses, Fluviá y Colera. Lo sabemos, porque el mismo conde, con fecha del 13 de junio del mismo año le envió «el dicho breve y una carta patente nuestra para los oficiales del dicho condado de Ampurias». Pero el abad de Montserrat le contestó que dicho breve «no estava como debía, por no tener facultad de quitar ninguno de los religiosos y poner otros». De manera que el conde hizo nuevas gestiones en Roma y obtuvo las facultades que pedía fray Pedro de Burgos, tal como se lo comunicó en carta del 27 de abril de $1517^{131}$.

La historia que sigue va más allá de la vida del Rey Católico, de manera que tal como estaba previsto los claustrales celebraron capítulo provincial en Sant Pau, donde dieron la bienvenida al procurador del monasterio de monjas de San Antón y Santa Clara, que tras una breve experiencia de la observancia vallisoletana (1514-18), volvieron a sujetarse a la Congregación Claustral Tarraconense.

De manera que la reforma observante iniciada en San Benito de Valladolid en 1390 fue agrupando poco a poco los monasterios benedictinos claustrales de la Provincia Benedictina Claustral de Toledo (Burgos y León) y luego los de la Provincia Benedictina Claustral Compostelana) Galicia y Asturias en los siglos XV-XVI, llegando a reunir a todos los monasterios existentes en España, merced a los esfuerzos reformadores de los Reyes Católicos, que intentaron

\footnotetext{
128 AAM, CI, vol. 11, ff. 86r-87v.

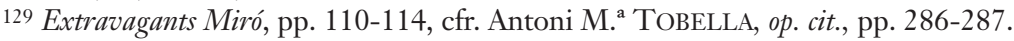

${ }^{130}$ Antoni M. ${ }^{\text {a }}$ TOBELLA, op. cit., p. 287.

${ }^{131}$ Gregorio de ARgaiz, La perla de Cataluña, op. cit., pp. 162-163; cfr. Ernesto ZaragOZA PASCUAL, Abaciologi Benedictí de la Tarraconense, op. cit., p. 267.
} 
también, especialmente con la colaboración de Fernando el Católico, la reforma de las abadías benedictinas de la Congregación Benedictina Claustral Tarraconense y Cesaraugustana, aunque sin el éxito clamoroso que tuvieron en Castilla, pues al fin, sólo dos monasterios aceptaron las observancias vallisoletanas, a saber el de Montserrat, el de Sant Feliu de Guíxols y temporalmente Sant Pau del Camp de Barcelona, cambiado luego por el de Sant Benet de Bages, que como colegio para los monjes de Montserrat continuó hasta la exclaustración de 1835 . 